\title{
Theoretical Study of Wood Microwave Pretreatment in Rectangular Cavity for Fabricating Wood-Based Nanocomposites
}

\author{
Yongfeng Luo, ${ }^{1} \mathrm{Xi} \mathrm{Li,},{ }^{1}$ Xianjun $\mathrm{Li}^{2}$ and Jianxiong Zhang ${ }^{1}$ \\ ${ }^{1}$ Institute of Mathematics and Physics, Central South University of Forestry and Technology, Changsha, Hunan 410004, China \\ ${ }^{2}$ Material Science and Engineering School, Central South University of Forestry and Technology, Changsha, Hunan 410004, China \\ Correspondence should be addressed to Xianjun Li; lxjmu@163.com
}

Received 24 April 2014; Accepted 14 June 2014; Published 2 July 2014

Academic Editor: Li Li

Copyright (C) 2014 Yongfeng Luo et al. This is an open access article distributed under the Creative Commons Attribution License, which permits unrestricted use, distribution, and reproduction in any medium, provided the original work is properly cited.

Modifying wood by high intensive microwave pretreatment method is widely researched for the fabrication of wood-based nanocomposites, but the temperature uniformity and energy efficiency of microwave pretreatment have not reached the ideal state. In this study, the pretreated wood in rectangular cavity by high intensive microwave is theoretically studied by the finite element method based on the Maxwell electromagnetic field equations and the heat and mass transfer theory. The results show that the temperature uniformity and energy efficiency are related to the microwave feeding modes. Compared with the single-port and the two-port feeding mode, the four-port feeding mode is the best case on temperature uniformity and energy efficiency. The optimized parameters of cavity to pretreatment wood are achieved, which are that the height of cavities is between $0.08 \mathrm{~m}$ and $0.11 \mathrm{~m}$ in the four-port feeding mode when the thickness of wood is $0.06 \mathrm{~m}$.

\section{Introduction}

Microwave pretreatment is a technique to improve process efficiency and product performance of wood in the forest product industry. High-intensity microwave pretreatment for wood modification originated from Australia $[1,2]$ at the end of last century, in which water in wood absorbed enough energy from the transient electromagnetic wave and turned into steam. High internal steam pressure destructed the weaker elements of wood and the microvoids in the radiallongitudinal planes of wood were created $[3,4]$, which puffed wood into loose structure, increased wood permeability, and improved the drying process. Some studies reported that several properties of wood were improved after microwave pretreatment. In Australia, Torgovnikov and Vinden's studies [57] showed that, after high-intensity microwave pretreatment, the permeability of the wood increased up to 14 -fold, the preservative penetration increased 10-14 times, the density of the wood reduced, and the elasticity modulus decreased
$12-17 \%$. As a result, a kind of wood with high permeability, low density, and good sound insulation was made, which was called puffing wood. And this treated wood could be used for new composites, such as the fabrication of wood-based nanocomposites and new functional materials [5-12]. To make the timber inorganic nanocomposites, direct infusion method is usually used, in which the composite compounds impregnate in wood cells cavity or walls through direct physical infusion method to make inorganic nanocomposites, such as various water-borne inorganic complex salt preservatives (boron preservative, boron-clay composite preservative, boron-silicon composite preservatives, basic zinc carbonate, copper oxide, sodium silicate, etc.) [13, 14], a variety of water-borne flame retardants (phosphorus-nitrogen boronbased flame retardants, amine-modified silicone-based flame retardants, phyllosilicates, etc.) [15-19]. This method of making the timber inorganic nanocomposites requires wood dried uniformly with large gap. Microwave pretreatment of wood can meet these requirements. As we know, the 
more even temperature profiles are, the better modification effect of wood will be. However, the most serious problem of the existing research is the nonuniformity of wood microwave modification. To solve this problem, we focused on related microwave pretreatment devices and the development of the microwave cavity with uniform distribution of microwave energy. The electromagnetic field distribution model and heat-mass transfer model are built for optimizing high-intensity microwave wood pretreatment process.

\section{Material and Methods}

In order to simulate the wood microwave heating process, some related models are created. There are two causes for the heat within wood during microwave heating. One part is the microwave absorbed by wood, which is described by absorption power of microwave, and the other is the heat transfer between each part of wood. Once the heat absorbed, heat transfer model, and its initial and boundary conditions are established, the temperature distribution within wood during microwave heating can be figured out. In the process of the simulation of high-intensity microwave heating, two parts are studied which are the distribution of electromagnetic wave and wood temperature in rectangle waveguide resonant cavity with different feeding modes. In order to simplify the calculation, some reasonable assumptions of the model are made as follows: the temperature and moisture are evenly distributed in the wood before heating. The air and wood in the cavity remain stationary during the heating process. Thirdly, wood is regarded as a homogeneous material. Finally, the moisture content and volume of wood remain unchanged while heating.

Finite element analysis is used to solve electromagnetic field and temperature distribution within wood. The microwave frequency is $0.915 \mathrm{GHz}$, and the length, width, and height of rectangular resonator cavity are $0.4953 \mathrm{~m}$, $0.24765 \mathrm{~m}$, and $0.08 \mathrm{~m}$, respectively. The total input power of microwave excitation sources is set at $40 \mathrm{~kW}$, which is averagely allocated to each excitation source. The waveguide of feeding port is a standard waveguide (Chinese national standard BJ9 model, length $0.24765 \mathrm{~m}$, width $0.12382 \mathrm{~m}$ ). Initial moisture content of wood is set at $60 \%$, the length, width, and height of the wood are set at $0.74295 \mathrm{~m}, 0.2 \mathrm{~m}$ and $0.06 \mathrm{~m}$, respectively, and the relative dielectric constant and dielectric loss factor are 7.40 and 1.42 , respectively. The initial temperature and the density are $25^{\circ} \mathrm{C}$ and $570 \mathrm{~kg} / \mathrm{m}^{3}$, respectively. The thermal conductivity $\lambda\left(\mathrm{W} / \mathrm{m}^{\circ} \mathrm{C}\right)$ and specific heat $C\left(\mathrm{~J} / \mathrm{kg}^{\circ} \mathrm{C}\right)$ depended on the following equations:

$$
\begin{gathered}
\lambda=0.23\left[1-\frac{0.72 \times(25-T)}{100}\right], \\
C=2650 \times\left(1+\frac{T}{100}\right)^{0.2} .
\end{gathered}
$$

\section{Theory}

While building the electromagnetic field and temperature distribution models, thermodynamics and Maxwell's electromagnetic theory are the foundation of the simulation.

3.1. The Distribution of the Electromagnetic Wave and Microwave Energy. According to Maxwell's equations, the electromagnetic field satisfies the following equations during microwave heating progress in the rectangular cavity:

$$
\begin{gathered}
\nabla \times \vec{E}=-\frac{\partial \vec{B}}{\partial t}, \\
\nabla \times \vec{H}=\vec{J}+\frac{\partial \vec{D}}{\partial t}, \\
\nabla \cdot \vec{B}=0, \\
\nabla \cdot \vec{D}=\rho_{c},
\end{gathered}
$$

where $\vec{E}$ is the electric field intensity, $\vec{H}$ is the magnetic field intensity, $\vec{B}$ is the magnetic induction intensity, $\vec{D}$ is the electric displacement, $\vec{J}$ is the current density, and $\rho_{c}$ is the free charge density, wherein $\vec{J}=\sigma \vec{E}, \vec{D}=\varepsilon \vec{E}, \vec{B}=\mu \vec{H}, \sigma$ is the conductivity, $\varepsilon$ is the dielectric constant, and $\mu$ is the magnetic permeability. According to (2), the distribution of the electromagnetic field inside the wood can be calculated [20].

In this study, the microwave excitation source is timeharmonic electromagnetic fields $\vec{E}_{10}$, where $\vec{E}=\vec{E}(x \vec{i}+y \vec{j}+$ $z \vec{k}) e^{-i \omega t}, \vec{H}=\vec{H}(x \vec{i}+y \vec{j}+z \vec{k}) e^{-i \omega t}, \vec{B}$ and $\vec{D}$ can be expressed as functions $\vec{E}$ and $\vec{H}$ :

$$
\begin{aligned}
\nabla \times \vec{E}(x \vec{i}+y \vec{j}+z \vec{k}) & =i \omega \mu \vec{H}(x \vec{i}+y \vec{j}+z \vec{k}), \\
\nabla \times \vec{H}(x \vec{i}+y \vec{j}+z \vec{k}) & =(\sigma-i \omega \varepsilon) \vec{E}(x \vec{i}+y \vec{j}+z \vec{k}) \\
& =-i \omega \varepsilon^{*} \vec{E}(x \vec{i}+y \vec{j}+z \vec{k}),
\end{aligned}
$$

where $\varepsilon^{*}$ is the complex permittivity, which can be expressed as $\varepsilon^{*}=\varepsilon^{\prime}+i \varepsilon^{\prime \prime}$. Equation (4) can be obtained from (3) [20]:

$$
\nabla\left(\vec{E} \cdot \frac{\nabla \varepsilon^{*}}{\varepsilon^{*}}\right)+\nabla^{2} \vec{E}+k^{2} \vec{E}=0
$$

By solving (4), the electric field distribution in wood can be obtained. In this study, we assumed that the wood dielectric is constant value along the direction of the electric field and the first term of (4) is zero, so (4) can be simplified as follows:

$$
\nabla^{2} \vec{E}+k^{2} \vec{E}=0
$$


where $k$ depends on the dielectric properties of wood and its expression is as follows:

$$
\begin{gathered}
k=\alpha+i \beta, \\
\alpha=\frac{2 \pi f}{c} \sqrt{\frac{\varepsilon^{\prime}\left(\sqrt{1+\tan ^{2} \delta}+1\right)}{2}}, \\
\beta=\frac{2 \pi f}{c} \sqrt{\frac{\varepsilon^{\prime}\left(\sqrt{1+\tan ^{2} \delta}-1\right)}{2}},
\end{gathered}
$$

where $f$ is the frequency of the microwave radiation and $\tan \delta$ is the wood loss factor; its value can be calculated from the following (7):

$$
\tan \delta=\frac{\varepsilon^{\prime \prime}}{\varepsilon^{\prime}} .
$$

In order to calculate the electric field distribution in wood, the solutions of (5) are obtained by the following boundary conditions:

$$
\begin{gathered}
n \times\left[\vec{E}_{1}(x \vec{i}+y \vec{j}+z \vec{k})-\vec{E}_{2}(x \vec{i}+y \vec{j}+z \vec{k})\right]=0, \\
n \times\left[\vec{H}_{1}(x \vec{i}+y \vec{j}+z \vec{k})-\vec{H}_{2}(x \vec{i}+y \vec{j}+z \vec{k})\right]=0,
\end{gathered}
$$

where the subscript 1 indicates air and the subscript 2 indicates wood. Equation (9) can also be expressed as a function of electric field intensity through the following expression:

$$
\frac{\partial \vec{E}(x)}{\partial x} \vec{i}+\frac{\partial \vec{E}(y)}{\partial y} \vec{j}+\frac{\partial \vec{E}(z)}{\partial z} \vec{k}=i \mu_{0} \omega \vec{H}(x \vec{i}+y \vec{j}+z \vec{k}) .
$$

The analytical solution of (5) is as follows:

$$
E=A_{1} e^{i k \sqrt{x^{2}+y^{2}+z^{2}}}+B_{1} e^{-i k \sqrt{x^{2}+y^{2}+z^{2}}},
$$

where $A_{1}$ and $B_{1}$ depend on the boundary conditions (8) and (9). The electric field in wood can be used to calculate the electromagnetic field energy density by Poynting theorem:

$$
Q=\frac{1}{2} \omega \varepsilon_{0} \varepsilon^{\prime \prime} \vec{E} \cdot \vec{E}^{*}
$$

where $\varepsilon_{0}$ is the permittivity of vacuum and $\vec{E}^{*}$ is the complex conjugate of the electric field.

3.2. Heat Transfer Model. In microwave pretreatment process, the microheat balance of wood is described by the following equation [20]:

$$
\rho C_{P} \frac{\partial T}{\partial t}=\nabla \cdot\left(k_{T} \nabla T\right)+Q,
$$

where $\rho, C_{P}$, and $k_{T}$ are density, specific heat, and thermal conductivity of wood, respectively, and $Q$ is electromagnetic energy density in the wood.
Boundary conditions of (13) are as follows [21]:

$$
\begin{array}{r}
t=0, \quad T=T_{\mathrm{ini}}, \quad 0 \leq x \leq L, \\
t>0, \quad-k_{T} \frac{\partial T}{\partial x}=h\left(T-T_{a}\right)+L_{\mathrm{vap}} k_{m}^{\prime}\left(C_{w, s}-C_{\text {equi }}\right), \\
x=L,
\end{array}
$$

where $x=0$ indicates the wood surface, $L$ is the width of the wood; $h$ is the heat transfer coefficient of the inner wood; $T_{a}$ and $T_{\mathrm{ini}}$ are air and wood initial temperature; $L_{\text {vap }}$ is the heat of vaporization of the water; $k_{m}^{\prime}$ is the mass transfer coefficient; $C_{w, s}$ is the moisture content of the wood surface; $C_{\text {equi }}$ is the equilibrium moisture content of the air.

3.3. Mass Transfer Model. To calculate the water concentration profile, the microscopic mass balance can be described by the following equation [22]:

$$
\frac{\partial C_{w}}{\partial t}=\nabla\left(D_{w} \nabla C_{w}\right),
$$

where $D_{w}$ is the effective diffusivity coefficient of the wood.

The boundary conditions of (15) are as follows:

$$
\begin{gathered}
t=0, \quad C_{w}=C_{w, \text { ini }}, \quad 0 \leq l \leq L, \\
t>0, \quad-D_{w} \frac{\partial C}{\partial x}=k_{m}^{\prime}\left(C_{w, s}-C_{\text {egui }}\right), \quad l=0, \quad l=L,
\end{gathered}
$$

where $C_{w \text {,ini }}$ is the wood initial moisture content.

\section{Results and Discussion}

4.1. Effect of Feeding Mode on Temperature Distribution and Energy Efficiency. The temperature distribution and energy efficiency of each feeding mode are obtained by computational simulation. The spatial distribution of temperature in feeding modes is studied (Figure 1). After being pretreated by microwave with the same power and time, the wood temperature of the single-port, the two-port, and the fourport feeding mode gradually increases. And this is due to the microwave distribution in the wood. High-temperature region distribution of the four-port feeding mode is dispersed; the temperature uniformity is better than the singleport and the two-port, feeding mode. But the temperature uniformity of the single-port and the two-port feeding mode could not be derived directly from the figure. As it can be seen from the three kinds of feeding modes, the highesttemperature region is not on the surface but inside the wood. And this is caused by the penetration of microwave, which means the microwave passes through the surface of the wood and occurs in strong interaction with the inner wood. The temperature distribution of single-port feeding mode appeared to be a "U," which is because the microwave feeding direction is oblique; the microwave energy distribution is uneven in the $y$-axis of wood. Figure 1 shows that temperature distribution in midsection is similar to the multisections. 


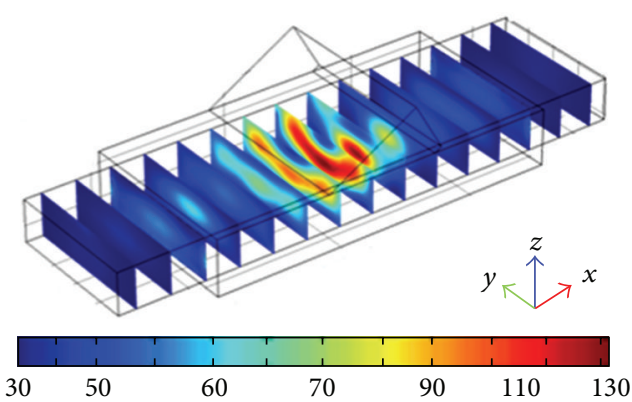

(a)

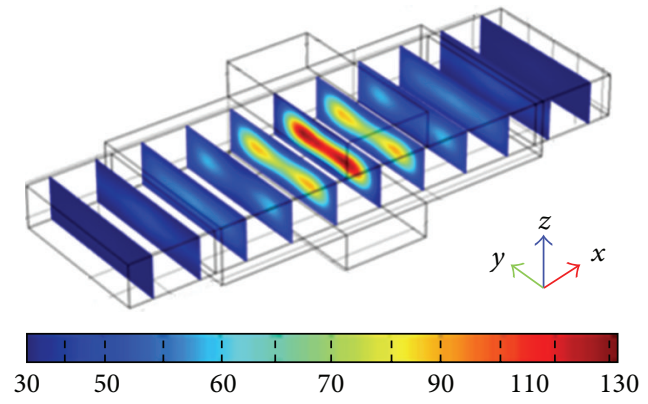

(b)

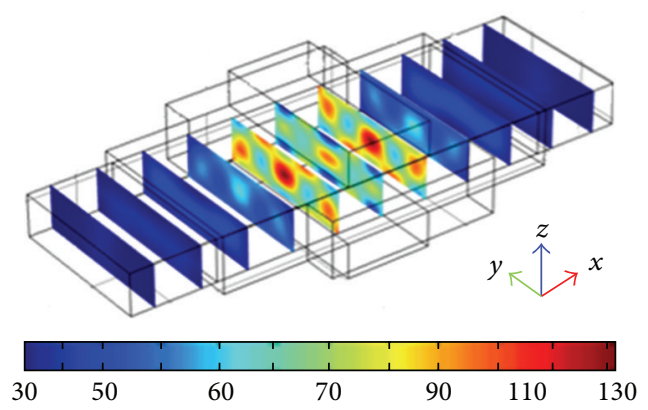

(c)

FIgURE 1: The multisections temperature $\left({ }^{\circ} \mathrm{C}\right)$ distribution within wood heated by microwave with different radiation methods. (a), (b), and (c) describe the single-port feeding mode, the two-port feeding mode, and the four-port feeding mode, respectively.

And most of the microwave energy is absorbed by the midsection of the wood. Thus, the midsection temperature distribution is studied specially.

Figure 2 shows that temperature in the bottom part of wood is the highest in the single-port feeding mode. This is due to the deeper penetration of microwave in the wood when there is only one feeding port. In the two-port feeding mode, temperature distribution is symmetric along $x y$ and $x z$ plane; the highest temperature region is in the center. And this is due to the fact that the microwave interference is formed when microwaves in both directions with the same phase position come cross each other. In the four-port feeding mode, temperature distribution is disperse; high temperature region is distributed uniformly. And this is because there is microwave energy from all directions in the four-port feeding mode. Figure 2 shows the temperature distribution uniformity roughly; in order to analyze the temperature uniformity

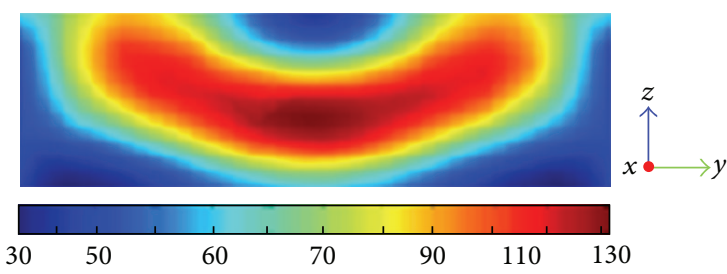

(a)

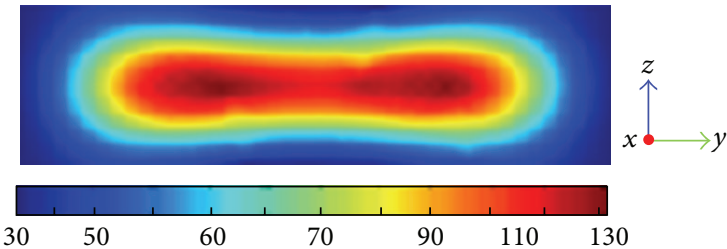

(b)

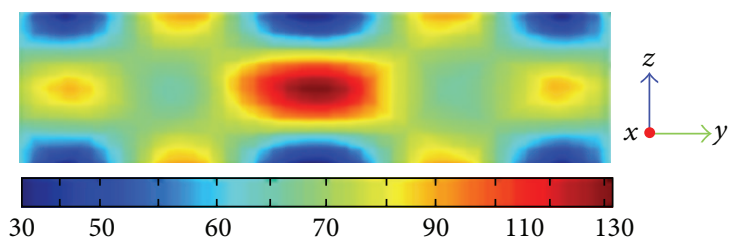

(c)

FIgURE 2: The midsection temperature $\left({ }^{\circ} \mathrm{C}\right)$ distribution within wood heated by microwave with different radiation methods. (a), (b), and (c) describe the single-port feeding mode, the two-port feeding mode, and the four-port feeding mode, respectively.

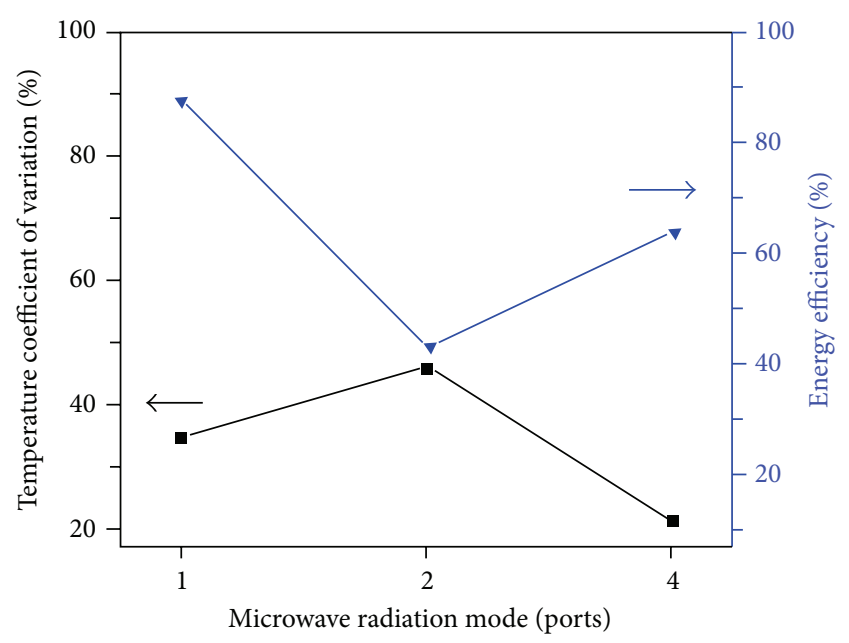

FIGURE 3: The effect of microwave radiation methods on temperature coefficient of variation and energy efficiency.

quantificationally, temperature coefficient of variation of the midsection temperature distribution within wood is studied. While energy efficiency is the ratio of energy absorbed in wood and whole input energy, which can reflect energy utilization and dissipation of resonator, the energy efficiency is very important on the performance evaluation of the cavity, which is taken into consideration too.

Each point of the midsection temperature is evenly selected, which is used to figure out temperature coefficient 


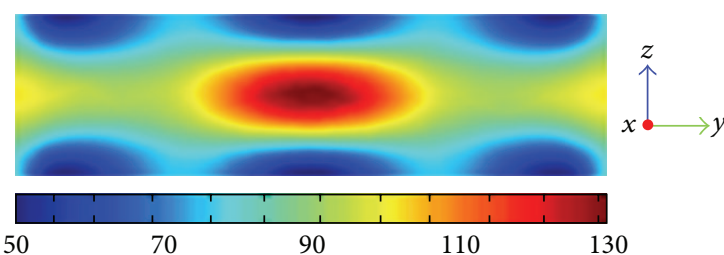

(a) $h=0.07(\mathrm{~m})$

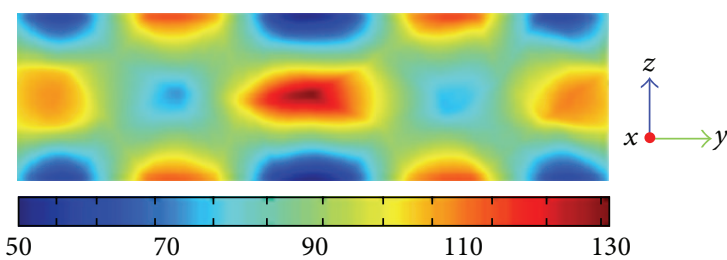

(c) $h=0.09(\mathrm{~m})$

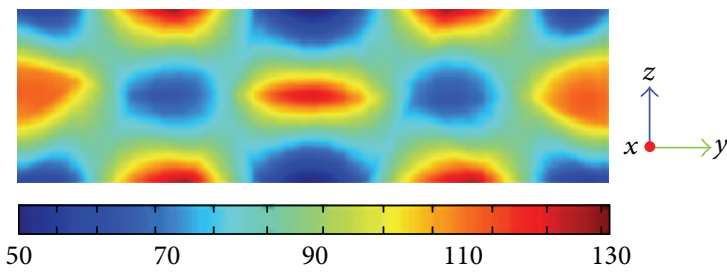

(e) $h=0.11(\mathrm{~m})$

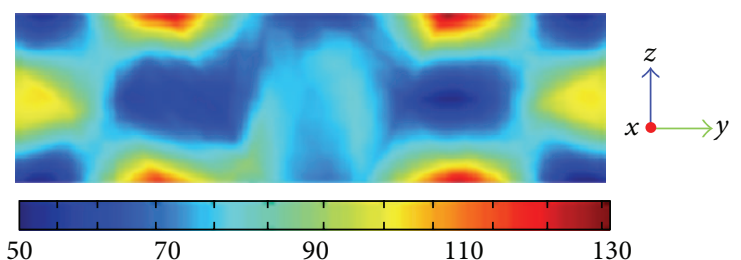

(g) $h=0.13(\mathrm{~m})$

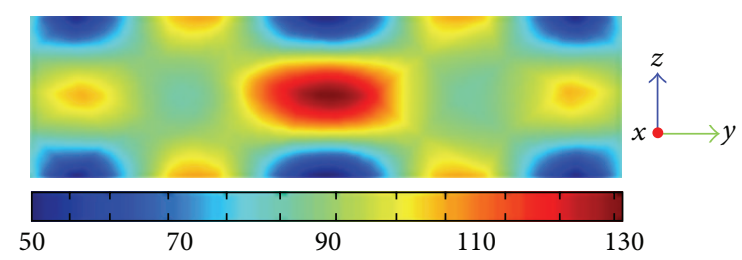

(b) $h=0.08(\mathrm{~m})$

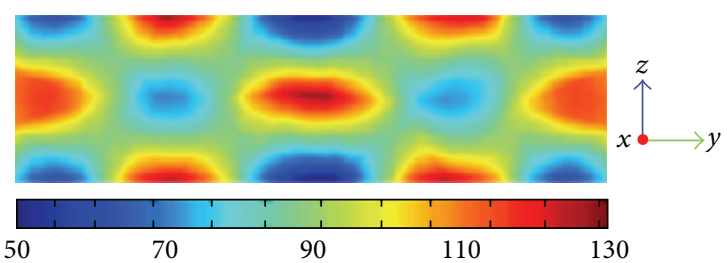

(d) $h=0.10(\mathrm{~m})$

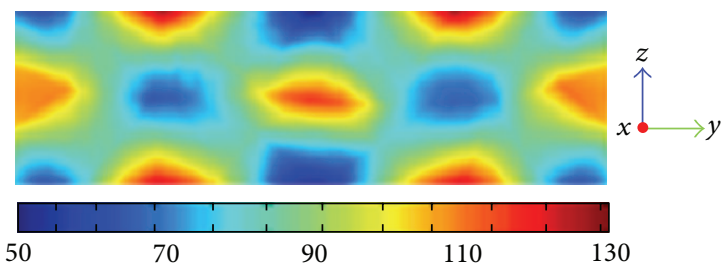

(f) $h=0.12(\mathrm{~m})$

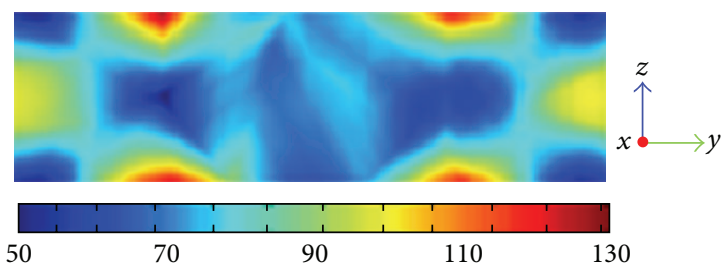

(h) $h=0.14(\mathrm{~m})$

FIgURE 4: The midsection temperature $\left({ }^{\circ} \mathrm{C}\right)$ distribution within wood heated by microwave with the four-port feeding mode.

of variation. Figure 3 shows the relation between temperature coefficient of variation, energy efficiency, and feeding mode. Figure 3 shows that energy efficiency of the single-port feeding mode is the highest, which is because the microwave feeding direction is oblique; microwave reflected several times in the microwave cavity; microwave can be fully absorbed by wood. But the microwave energy is relatively divergent, causing the uneven temperature distribution. Therefore, temperature coefficient of variation is larger. In the two-port feeding mode, temperature coefficient of variation is the largest, while energy efficiency dropped below 50\%, which is not conducive to wood microwave pretreatment. In the four-port feeding mode, temperature coefficient of variation improved on the basis of the single-port feeding mode, reduced to nearly 20 percent. The temperature uniformity has been greatly improved, while energy efficiency is also high. Considering Figures 3 and 4 synthetically, high temperature region is distributed dispersedly and uniformly in the fourport feeding mode. And temperature coefficient of variation is small, which is in favor of rapid and uniform drying of wood. Thus, four-port feeding mode is the best choice in the three feeding modes. It also shows that the temperature uniformity do not improved as the feeding ports increasing, and the energy efficiency is not related to the feeding ports. The reason of temperature uniformity and energy efficiency is complicated, which is not only decided by the number of feeding ports.

\subsection{Effect of the Height of Cavities on Temperature Distribution} and Energy Efficiency. Electromagnetic field distribution is influenced by the height of cavity (" $h$ " for short), which has some influence on the heating effect. In order to determine the best height of cavity when thickness of the wood is $0.06 \mathrm{~m}$, the respective temperature distribution of the wood is studied when the height of cavity is $0.07,0.08,0.09,0.10,0.11,0.12,0.13$, and $0.14 \mathrm{~m}$. Because the thickness of the actual wood always changes in the size, only the roughly height range of cavity needs to be determined.

Figure 4 shows the effect of the height of cavities on the midsection temperature distribution. High temperature region is gradually diverging from the center to the edge as the height of the cavity increases. When $h \geq 0.11 \mathrm{~m}$, the temperature of the edge area is gradually higher than in the central region, which is not conducive to wood microwave pretreatment. So the height of microwave cavity should be $h<0.11 \mathrm{~m}$. Figure 4 shows that when $h \leq 0.08 \mathrm{~m}$, high 


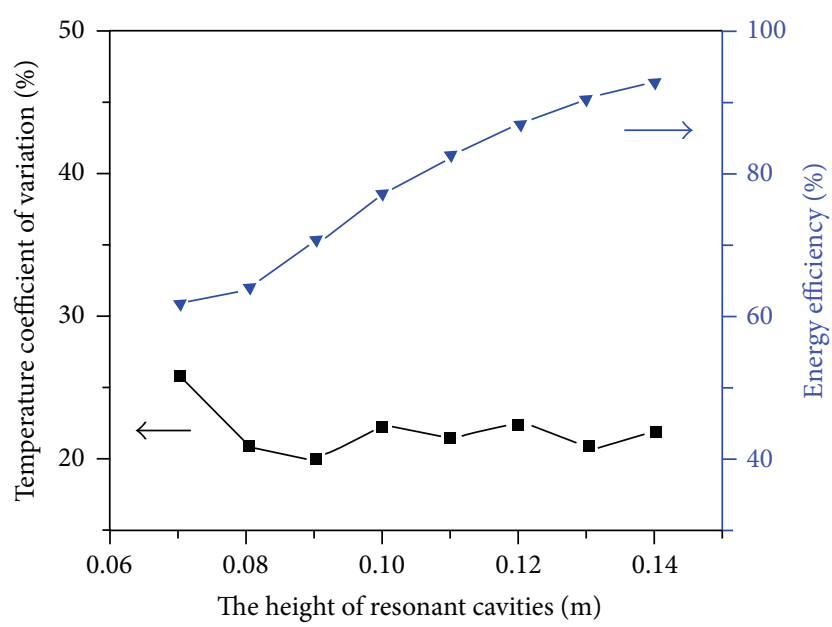

FIgURE 5: The effect of the height of cavities on temperature coefficient of variation and energy efficiency.

temperature region is too concentrated in the center, which might cause damage to the center of the wood. And the temperature distribution is uneven, so the height of cavity should be $h>0.08 \mathrm{~m}$.

Figure 5 shows the relation between temperature coefficient of variation, energy efficiency, and feeding mode as height of the cavity changes. Figure 5 shows that when $h \leq 0.08 \mathrm{~m}$, temperature coefficient of variation is very large; thus the temperature distribution is uneven. At the same time, energy efficiency is very low. As height of the cavity increases, energy efficiency which is determined by the shape of the cavity and the wavelength is also increasing. While considering the temperature distribution within the wood, $h$ should not be too large. Using comprehensive analysis of temperature uniformity, drying efficiency, and energy efficiency, the ranges of the cavity height should be $0.08 \mathrm{~m}<h<0.11 \mathrm{~m}$. It also shows that the energy efficiency improves with the cavity heightening, while the temperature uniformity remains almost unchanged. This is because when the volume of the cavity became larger, the distance of each feeding port became longer and electromagnetic leakage is less through feeding ports.

\section{Conclusion}

Effect of different feeding modes on wood microwave pretreatment is simulated and optimized parameters of cavity are achieved. Considering the wood temperature coefficient of variation and energy efficiency on different heating cavities, the following conclusions were made. Firstly, four-port feeding mode is the best among the three feeding modes on temperature uniformity and energy efficiency, and the height of cavities between $0.08 \mathrm{~m}$ and $0.11 \mathrm{~m}$ is the optimized parameter for wood whose thinness is $0.06 \mathrm{~m}$. Temperature uniformity do not improve as the feeding ports increase, and energy efficiency is not related to the feeding ports. Lastly, energy efficiency improved with the heating cavity heightening, while temperature uniformity remains almost unchanged.

\section{Conflict of Interests}

The authors declare that there is no conflict of interests regarding the publication of this paper.

\section{Acknowledgments}

The authors acknowledge the support of the Special Fund for Forest Scientific Research in the Public Welfare (no. 201204708), National Natural Science Foundation of China (no. 31370564), New-Century Training Program Foundation for the Talents by the Ministry of Education of China (NCET-11-0979), and Graduate Student Innovation Fund of Central South University of Forestry and Technology (no. CX2014B20).

\section{References}

[1] I. W. Turner, J. R. Puiggali, and W. Jomaa, "A numerical investigation of combined microwave and convective drying of a hygroscopic porous material: a study based on pine wood," Chemical Engineering Research and Design, vol. 76, no. 2, pp. 193-209, 1998.

[2] A. Oloyede and P. Groombridge, "Influence of microwave heating on the mechanical properties of wood," Journal of Materials Processing Technology, vol. 100, no. 1, pp. 67-73, 2000.

[3] X. Li, Y. Zhou, Y. Yan, Z. Cai, and F. Feng, "A single cell model for pretreatment of wood by microwave explosion," Holzforschung, vol. 64, no. 5, pp. 633-637, 2010.

[4] Z. YongDong, F. Feng, L. XianJun, J. XiaoMei, and C. ZhiLin, "Effects of microwave treatment on residue growth stress and microstructure of Eucalyptus urophylla," Journal of Beijing Forestry University, vol. 31, no. 2, pp. 146-150, 2009.

[5] G. Torgovnikov and P. Vinden, "Microwave wood modification technology and its applications," Forest Products Journal, vol. 60, no. 2, pp. 173-182, 2010.

[6] G. Torgovnikov and P. Vinden, "High-intensity microwave wood modification for increasing permeability," Forest Products Journal, vol. 59, no. 4, pp. 84-92, 2009.

[7] S. R. Przewloka, J. A. Hann, and P. Vinden, "Assessment of commercial low viscosity resins as binders in the wood composite material Vintorg," Holz als Roh-und Werkstoff, vol. 65, no. 3, pp. 209-214, 2007.

[8] K. Sugiyanto, P. Vinden, G. Torgovnikov, and S. Przewloka, "Microwave surface modification of Pinus radiata peeler cores: technical and cost analyses," Forest Products Journal, vol. 60, no. 4, pp. 346-352, 2010.

[9] G. Torgovnikov and P. Vinden, "New $300 \mathrm{~kW}$ plant for microwave wood modification," in Proceedings of the International Microwave Power Institutes 40th Annual Symposium, pp. 260-263, Boston, Mass, USA, 2006.

[10] P. Vinden, G. Torgovnikov, and J. Hann, "Microwave modification of Radiata pine railway sleepers for preservative treatment," European Journal of Wood and Wood Products, vol. 69, no. 2, pp. 271-279, 2011.

[11] Y. Guangming, L. Yuan, and H. Yunchu, "Research on dispersing and surface treatment of inorganic-nanoparticles used for 
wood/inorganic-nano-composite," Wuhan Ligong Daxue Xuebo Jiaotong Kexue Yu GongchengBan, vol. 32, no. 1, pp. 142-145, 2008 (Chinese).

[12] G. Yuan, Y. Liu, Y. Wu, Y. Hu, and Z. Wu, "Study on structure characterization and combining mechanism of Chinese fir/nano SiO2 composite," Journal of Hunan University Natural Sciences, vol. 36, no. 9, pp. 59-62, 2009 (Chinese).

[13] D. N. Obanda, T. F. Shupe, and H. M. Barnes, "Reducing leaching of boron-based wood preservatives-a review of research," Bioresource Technology, vol. 99, no. 15, pp. 7312-7322, 2008.

[14] S. N. Kartal, T. Yoshimura, and Y. Imamura, "Modification of wood with Si compounds to limit boron leaching from treated wood and to increase termite and decay resistance," International Biodeterioration and Biodegradation, vol. 63, no. 2, pp. 187-190, 2009.

[15] E. Baysal, M. Altinok, M. Colak, S. Kiyoka Ozaki, and H. Toker, "Fire resistance of Douglas fir (Pseudotsuga menzieesi) treated with borates and natural extractives," Bioresource Technology, vol. 98, no. 5, pp. 1101-1105, 2007.

[16] A. M. Pereyra and C. A. Giudice, "Flame-retardant impregnants for woods based on alkaline silicates," Fire Safety Journal, vol. 44, no. 4, pp. 497-503, 2009.

[17] S. N. Kartal, W.-J. Hwang, A. Yamamoto, M. Tanaka, K. Matsumura, and Y. Imamura, "Wood modification with a commercial silicon emulsion: effects on boron release and decay and termite resistance," International Biodeterioration \& Biodegradation, vol. 60, no. 3, pp. 189-196, 2007.

[18] A. Ciudad, A. M. Lacasta, L. Haurie, J. Formosa, and J. M. Chimenos, "Improvement of passive fire protection in a gypsum panel by adding inorganic fillers: Experiment and theory," Applied Thermal Engineering, vol. 31, no. 17-18, pp. 3971-3978, 2011.

[19] P. Kiliaris and C. D. Papaspyrides, "Polymer/layered silicate (clay) nanocomposites: an overview of flame retardancy," Progress in Polymer Science, vol. 35, no. 7, pp. 902-958, 2010.

[20] K. G. Ayappa, "Modelling transport processes during microwave heating: a review," Reviews in Chemical Engineering, vol. 13, no. 2, pp. 1-69, 1997.

[21] L. A. Campañone, C. A. Paola, and R. H. Mascheroni, "Modeling and simulation of microwave heating of foods under different process schedules," Food and Bioprocess Technology, vol. 5, no. 2, pp. 738-749, 2012.

[22] F. Marra, M. V. De Bonis, and G. Ruocco, "Combined microwaves and convection heating: a conjugate approach," Journal of Food Engineering, vol. 97, no. 1, pp. 31-39, 2010. 

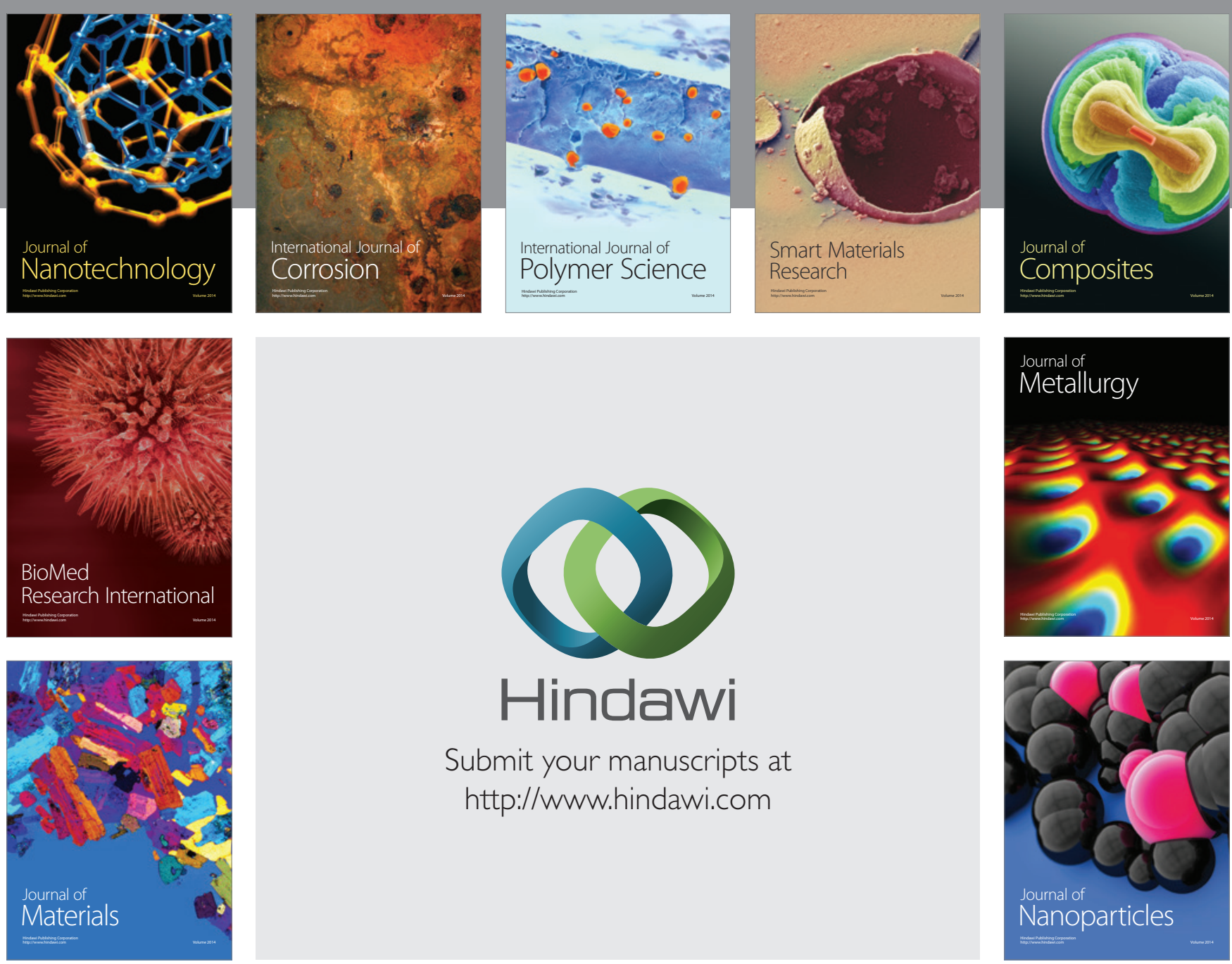

Submit your manuscripts at http://www.hindawi.com
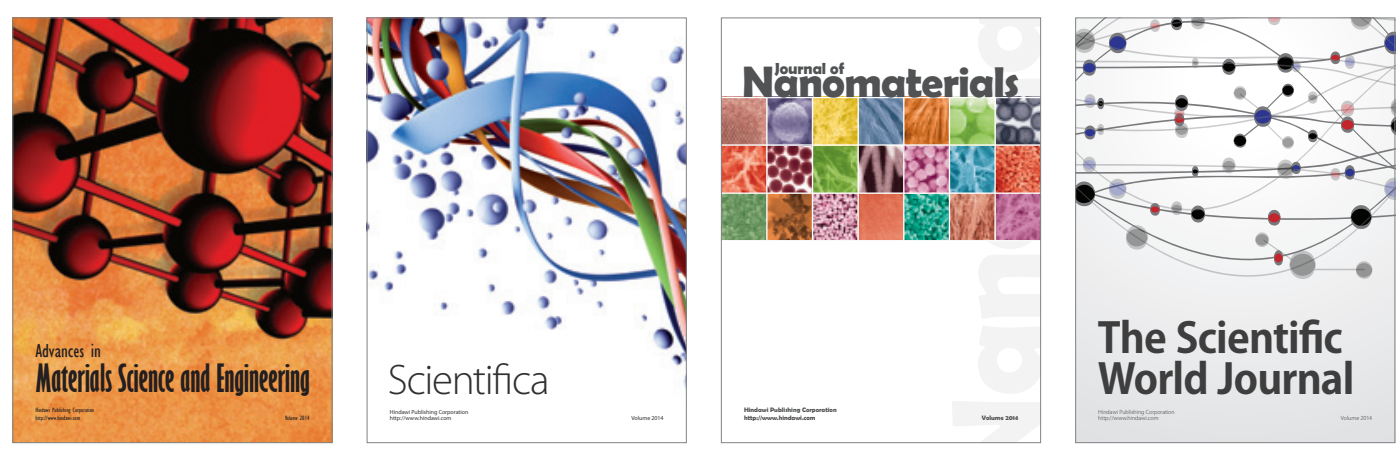

\section{The Scientific World Journal}
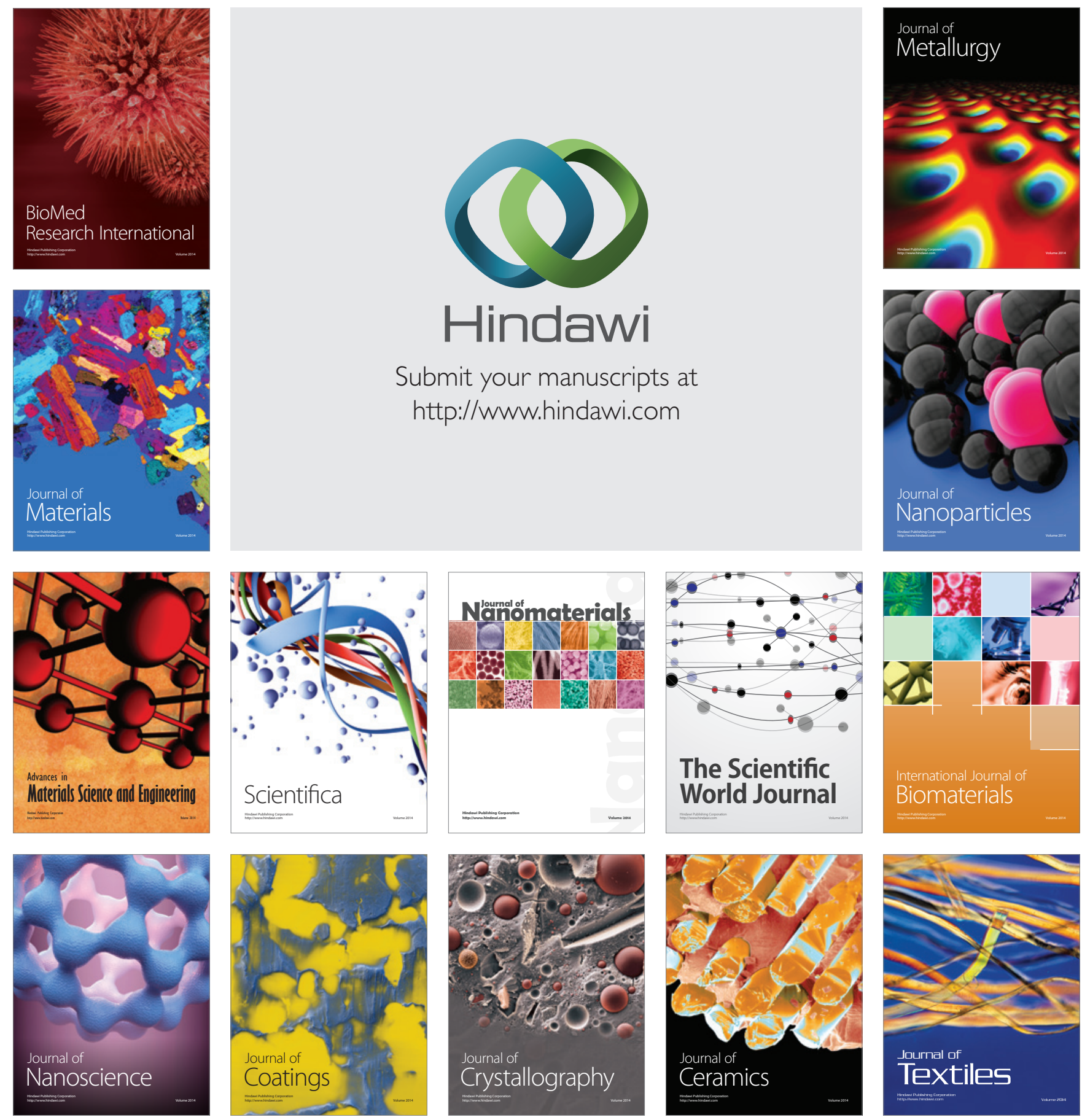